\title{
Sorghum dwarfing genes can affect radiation capture and radiation use efficiency
}

\author{
B. George-Jaeggli a,*, D.R. Jordan ${ }^{\text {b }}$, E.J. van Oosterom ${ }^{\text {c }}$, I.J. Broad ${ }^{\text {d }}$, G.L. Hammer ${ }^{\mathrm{e}}$ \\ a Queensland Department of Agriculture, Fisheries and Forestry, Hermitage Research Facility, 604 Yangan Road, Warwick, Qld 4370, Australia \\ ${ }^{\mathrm{b}}$ The University of Queensland, Queensland Alliance for Agriculture and Food Innovation, Hermitage Research Facility, Warwick, Qld 4370, Australia \\ ' The University of Queensland, School of Agriculture and Food Sciences, Queensland Alliance for Agriculture and Food Innovation Brisbane, QLD 4072, \\ Australia \\ ${ }^{\mathrm{d}}$ Queensland Department of Agriculture, Fisheries and Forestry, PO Box 102, Toowoomba, Qld 4350, Australia \\ e The University of Queensland, Queensland Alliance for Agriculture and Food Innovation, Brisbane, QLD 4072, Australia
}

\section{A R T I C L E I N F O}

\section{Article history:}

Received 24 April 2012

Received in revised form 2 May 2013

Accepted 2 May 2013

\section{Keywords:}

Light interception

Plant height

Radiation use efficiency

Sorghum bicolor

\begin{abstract}
A B S T R A C T
Presence of the $d w 3$ sorghum dwarfing gene had negative effects on grain yield in some genetic backgrounds and environments. In a previous study we showed that this was due to a significant reduction in shoot biomass (mainly via reduced stem mass), which in turn negatively affected grain size. The current study examines whether shoot biomass was reduced via effects of $d w 3$ on traits associated with resource capture, such as leaf area index (LAI), light interception (LI), and canopy extinction coefficient $(k)$ or with resource use efficiency, such as radiation use efficiency (RUE). Three pairs of near-isogenic sorghum lines differing only in the presence or absence of the dwarfing allele $d w 3$ (3-dwarfs vs 2-dwarfs) were grown in large field plots. Biomass accumulation and LI were measured for individual canopy layers to examine canopy characteristics of tall and short types. Similar to the previously reported effects on grain yield, the effects of $d w 3$ on RUE, LI and $k$ varied among genetic backgrounds and environments. Interactions between $d w 3$ and genetic background, but also interactions with environment are likely to have modulated the extent to which RUE, LI, or $k$ contributed to biomass differences between tall and short sorghum.
\end{abstract}

Crown Copyright @ 2013 Published by Elsevier B.V. All rights reserved.

\section{Introduction}

A positive correlation between plant height and grain yield is often reported for sorghum (Graham and Lessman, 1966; Campbell and Casady, 1969; Doggett, 1988; Morgan and Finlayson, 2000; Jordan et al., 2003). Partly this is due to a direct negative effect of the presence of the sorghum dwarfing gene $d w 3$ on grain yield (Hadley et al., 1965; Casady, 1967; Campbell and Casady, 1969; Campbell et al., 1975). The two most widely used dwarfing genes in wheat, Rht-B1b and Rht-D1b, on the other hand, are generally associated with higher grain yield per plant (Austin et al., 1980; Gale and Youssefian, 1985; Borner et al., 1993; Flintham et al., 1997). This has been attributed to only moderate reduction in overall plant biomass and reduced competition from the stem leading to improved floret fertility and consequently increased grain number in the presence of either of these dwarfing genes (Gale and

\footnotetext{
* Corresponding author. Tel.: +61 74660 3642; fax: +61 746603600 .

E-mail addresses: Barbara.George-Jaeggli@daff.qld.gov.au (B. George-Jaeggli), David.R.Jordan@daff.qld.gov.au (D.R. Jordan), erik.van.oosterom@uq.edu.au (E.J. van Oosterom), Ian.Broad@daff.qld.gov.au (I.J. Broad), g.hammer@uq.edu.au (G.L. Hammer).
}

Youssefian, 1985; Miralles et al., 1998). More recently, some of the gibberellin-responsive wheat dwarfing genes Rht4, Rht12 and Rht13 have also been found to have positive effects on grain number (Rebetzke et al., 1999).

In a recent sorghum study, reduced competition from the stem due to the presence of the $d w 3$ dwarfing gene had no positive effect on grain number (George-Jaeggli et al., 2011), most likely because this was off set by a reduction in crop growth rate, resulting in little effect on panicle growth rate and hence grain number (van Oosterom and Hammer, 2008). Rather, the presence of $d w 3$ was associated with reduced grain size, which negatively affected grain yield in some genotypes and environments (George-Jaeggli et al., 2011). More importantly, in some cases the effects of $d w 3$ on overall plant biomass were rather large, mainly due to large reductions in stem mass, but to a lesser extent also related to a negative effect of $d w 3$ on tiller mass (George-Jaeggli et al., 2011). Under wellwatered conditions, biomass accumulation is the product of light interception (LI) and radiation use efficiency (RUE). LI is a function of leaf area index (LAI) and canopy light extinction coefficient $(k)$ (Beer-Lambert-Boguer Law).

Earlier studies found no difference in light interception between tall 2-dwarf sorghum genotypes and that of shorter 3-dwarf types (Graham and Lessman, 1966). Interestingly though, a very tall, 
1-dwarf sorghum hybrid was reported to have significantly greater radiation use efficiency (RUE, above-ground biomass produced per unit light intercepted) than standard 3-dwarf hybrids (Hammer et al., 2010). In the absence of stress, RUE is mainly dependent on maximum leaf photosynthetic rate and generally shows very little within-species variation (Sinclair and Muchow, 1999). The RUE calculated for the 1-dwarf sorghum hybrid was closer to the value of $1.6-1.7 \mathrm{~g} \mathrm{MJ}^{-1}$ (based on total solar radiation) usually reported for maize (Sinclair and Muchow, 1999) and therefore more than $20 \%$ greater than the values of $1.2-1.3 \mathrm{~g} \mathrm{MJ}^{-1}$ normally reported for grain sorghum (Muchow and Davis, 1988; Muchow and Sinclair, 1994; Sinclair and Muchow, 1999; Gilbert et al., 2003). RUE values reported for sugarcane, another $\mathrm{C} 4$ species, were also similar to the values found in maize (Sinclair and Muchow, 1999). Commercial grain sorghum hybrids are generally much shorter than maize or sugarcane crops, but also much shorter than the material they originated from. Up to four dwarfing genes are combined in countries where machine harvesting prevails, reducing plant height from up to $4 \mathrm{~m}$ down to around $60 \mathrm{~cm}$ (Doggett, 1988). It is curious therefore that the 1-dwarf sorghum, which was of similar height as a maize crop, had a $20 \%$ greater RUE than grain sorghum crops of standard height. This raises the question whether plant height might affect RUE. To study the effects of height separate from the effects of other genes, we used isogenic lines that differed in just one allele $(d w 3)$.

The objective of this study was to determine whether a reduction in shoot biomass in response to $d w 3$ was associated with reduced RUE or reduced radiation capture (LAI, LI or $k$ ).

\section{Materials and methods}

\subsection{Plant material}

Standard sorghum grown in industrialised countries is usually recessive at three of four known dwarfing loci reducing plant heights of up to $4 \mathrm{~m}$ to a more manageable $90 \mathrm{~cm}$ (Doggett, 1988). Because dwarfing genes are loss-of-function mutations (Quinby and Karper, 1954), but one of the dwarfing alleles $(d w 3)$ is unstable and frequently reverts back to its tall wildtype (Multani et al., 2003), we were able to develop isogenic pairs that differed just by one dwarfing gene from three different inbred lines R931945-2-2, R955343-1, and R955637 (George-Jaeggli et al., 2011). Each dwarfing gene can reduce plant height by as much as $50 \mathrm{~cm}$ depending on genetic background and presence of other dwarfing genes (Quinby and Karper, 1945). Because we used spontaneous reverse mutations in 3-dwarf backgrounds, we were comparing near-isogenic 2dwarfs (tall) and 3-dwarfs (short) in different backgrounds. Within these near-isogenic pairs we refer to stature (tall and short) as the effects of the absence or presence of $d w 3$. For two of these inbred lines (R931945-2-2 and R955637), near-isogenic pairs were used to produce F1 hybrids, by crossing the inbred lines with A923171, an elite cytoplasmic male sterile female line from the Queensland breeding programme. R931945-2-2 is a low-tillering, elite male parent line used in the public sorghum breeding programme in Queensland. R955343-1 and R955637 are two male parent lines with moderate tillering. In addition, an unrelated 1-dwarf hybrid from India (CSH13R) and one of its parental lines (RS29) (which are both 1-dwarfs and therefore taller than the 2-dwarfs), were included in Experiment 2 to see whether the previously reported high radiation use efficiency of CSH13R (Hammer et al., 2010) was associated with a change in the canopy extinction coefficient.

\subsection{Experimental details}

Three field experiments were conducted between 2001 and 2004 at Hermitage Research Facility $\left(28^{\circ} 12^{\prime}\right.$ S, $152^{\circ} 06^{\prime}$ E; 470 m above sea level) near Warwick, Queensland, in eastern Australia. Experiments were sown on 24 October 2001 (Exp1), 5 November 2002 (Exp2), and 18 November 2003 (Exp3) and harvested at physiological maturity. Average maximum daily temperatures during the experiments ranged from $28.6^{\circ} \mathrm{C}(\operatorname{Exp} 1)$ to $30.5^{\circ} \mathrm{C}(\operatorname{Exp} 2)$, and minimum daily temperatures ranged from $14.3^{\circ} \mathrm{C}(\operatorname{Exp} 2$ and Exp3) to $14.9^{\circ} \mathrm{C}$ (Exp1). Exp3 had the lowest mean daily solar radiation $\left(21.4 \mathrm{MJ} \mathrm{m}^{-2}\right)$, lowest pan evaporation $(6.1 \mathrm{~mm})$, and highest relative humidity (66.4\%). Exp1 (23.7 $\mathrm{MJ} \mathrm{m}^{-2}$ ) had higher mean daily solar radiation than $\operatorname{Exp} 2\left(22.3 \mathrm{MJ} \mathrm{m}^{-2}\right)$, but the two experiments had similar mean daily pan evaporation $(6.8 \mathrm{~mm})$, whereas mean daily relative humidity was slightly lower in Exp1 (58.9\%) than Exp2 (60.2\%). The mean maximum temperature until anthesis was lower in $\operatorname{Exp} 1\left(27.0^{\circ} \mathrm{C}\right)$ than in $\operatorname{Exp} 2\left(31.2^{\circ} \mathrm{C}\right)$ and $\operatorname{Exp} 3\left(30.5^{\circ} \mathrm{C}\right)$, but the average minimum temperature until anthesis was similar across experiments $\left(13.2-13.6^{\circ} \mathrm{C}\right)$.

The experiments were conducted under non-limiting nutrient conditions and were planted on full profiles of subsoil moisture. The experiments were irrigated as soon as an estimated deficit of $30 \mathrm{~mm}$ was reached, to prevent any water limitation. Exp1 experienced some water limitation towards harvest. In Exp1, $300 \mathrm{~kg} \mathrm{ha}^{-1}$ of superphosphate with copper and zinc, $100 \mathrm{~kg} \mathrm{ha}^{-1}$ of muriate of potash, and $120 \mathrm{~kg} \mathrm{ha}^{-1}$ of $\mathrm{N}$ were applied at sowing. A further $60 \mathrm{~kg} \mathrm{ha}^{-1}$ of $\mathrm{N}$ was applied at both floral initiation and anthesis. As the soil profile for Exp2 and Exp3 already contained $390 \mathrm{~kg} \mathrm{ha}^{-1}$ from an earlier fertiliser application, $163 \mathrm{~kg} \mathrm{ha}^{-1}$ of $\mathrm{N}$ and $7 \mathrm{~kg} \mathrm{ha}^{-1}$ of zinc were applied prior to sowing of both experiments and a further $45 \mathrm{~kg} \mathrm{ha}^{-1}$ of Granulock (Incitec, N 10.5\%, P 19.5\%, S 2.2\%, $\mathrm{Z} 2.5 \%)$ was applied at sowing. Weeds and insect pests were controlled as required.

Plots were eight rows wide with $0.75 \mathrm{~m}$ row spacing. Plot length was $10 \mathrm{~m}$ in Exp1 and Exp3 and $20 \mathrm{~m}$ in Exp2. The row orientation was approximately north to south. To eliminate shading effects from neighbouring plots, only the middle four rows were used for measurements. Two further guard rows between all plots were planted with a commercial 3-dwarf hybrid. All plots were thinned to 10 plants $\mathrm{m}^{-2}$ around two weeks after emergence.

Treatments in each experiment consisted of the factorial combination of 2-dwarf and 3-dwarf isolines. Exp1 was laid out as completely randomised blocks with three replicates and consisted of two hybrid pairs (A923171/R931945-2-2 $\pm d w 3$ and A923171/R955637 $\pm d w 3$ ) and two inbred line pairs (R931945$2-2 \pm d w 3$ and $\mathrm{R} 955637 \pm d w 3)$. In Exp2 and Exp3, treatments (genetic background $\times$ stature) were arranged in latinised rowcolumns with four replicates. Exp2 contained two inbred line pairs (R931945-2-2 $\pm d w 3$ and R955637 $\pm d w 3$ ) and Exp3 contained one hybrid pair (A923171/R931945-2-2 $\pm d w 3$ ) and two inbred line pairs (R931945-2-2 $\pm d w 3$ and R955343-1 $\pm d w 3$ ). In addition, CSH13R and its parental line RS29 (both 1-dwarf) were grown in Exp2 but not used in the factorial analysis.

\subsection{Biomass samples}

In each experiment, biomass samples were collected during early growth (40, 29 and 30 days after sowing (DAS) in Exp1, 2 and 3 respectively) and at anthesis (70-75 DAS). A further three harvesting dates were added in Exp2 for the calculation of the canopy light extinction coefficient (43, 53 and 85 DAS). For each biomass sample, plants from $1 \mathrm{~m}$ row were cut at ground level from the four centre rows per plot $\left(3 \mathrm{~m}^{2}\right)$.

In the laboratory, a representative subsample was used for detailed measurements. Green leaf area was measured with an electronic planimeter (DIAS image analysis system, Delta-T Devices Ltd., Cambridge, UK). In Exp2, biomass samples were divided into five canopy strata of $20 \mathrm{~cm}$ (3-dwarfs), $30 \mathrm{~cm}$ (2-dwarfs) and $50 \mathrm{~cm}$ (1-dwarfs) for estimation of the canopy extinction coefficient $(k)$. 
Plant samples were dried in a forced-draft oven at $80^{\circ} \mathrm{C}$ until no further mass loss was detected.

\subsection{Light interception measurements}

In all three field experiments, tube solarimeters (Delta-T Devices, Cambridge, UK) coupled to a data logger (CR10X, Campbell Scientific Inc., Logan, USA) and calibrated against a reference solarimeter, were used to measure total intercepted radiation $\left(\mathrm{MJ} \mathrm{m}^{-2}\right)$. Solarimeters were placed at ground level and positioned at an angle between two rows so that each end was directly under a row of plants and the solarimeter covered the inter-row space. Senesced leaves on plants around the solarimeters were removed on a regular basis. To estimate the canopy light extinction coefficient $k$, plots in two replicates of Exp2 were equipped with racks that held multiple solarimeters, to measure transmitted radiation of five different canopy strata. The racks were orientated similarly to the ground solarimeters and in a manner that ensured minimum shading of the tube solarimeters by the structure of the racks.

Fractional light transmission was calculated as the ratio of the reading for each solarimeter inside the canopy to that for the reference tube above the canopy. The fraction intercepted light was calculated as one minus the fraction transmitted. The daily integral of incident shortwave radiation $\left(\mathrm{MJ} \mathrm{m}^{-2}\right)$ was measured via a calibrated pyranometer (CM 11/14, Kipp\&Zonen, Delft, Holland), located in a meteorological station adjacent to the experiment. The calculated fraction of intercepted radiation and the measured daily total incident radiation were used to calculate daily intercepted radiation by the crop.

To augment the continuous measurements of light interception measured with the solarimeter racks that were installed in two replicates only, spot interception readings were taken with a PAR80 linear ceptometer (Decagon Devices Inc., Pullman, Washington) in all replicates.

\subsection{Radiation use efficiency}

The efficiency with which intercepted radiation is used to produce biomass is defined as radiation use efficiency (RUE) (Sinclair and Muchow, 1999). It can be estimated from the ratio of accumulated biomass ( $\Delta$ Biomass) to cumulative light interception $(\Delta \mathrm{LI})$ during a defined period of time (Eq. (1)).

RUE $=\frac{\Delta \text { Biomass }}{\Delta \text { LI }}$

Accumulated biomass was calculated for each plot as the difference in biomass between a biomass sample taken during early growth (at 29-40 DAS, depending on Exp) and another sample taken at anthesis. Corresponding cumulative light interception by the entire canopy of that plot was calculated for the same period.

\subsection{Canopy light extinction coefficient $(k)$}

Cumulative LAI (from the top of the canopy) and daily integrated light interception of the various strata were used to estimate $k$ in Exp2. Data from the spot measurements (ceptometer) in all replicates were used to augment the continuous solarimeter measurements from two replicates. The value of $k$ for each genotype and harvest date was calculated by fitting a non-linear regression of cumulative fractional interception on cumulative LAI throughout the canopy using Eq. (2), derived from the Beer-Bouguer-Lambert Law (Monsi and Saeki, 1953).

$\mathrm{LI}=\mathrm{LI}_{\max }\left(1-\exp ^{(-k \times \mathrm{LAI})}\right)$

where LI and LAI are cumulative fractional light interception and leaf area index from the top of the canopy, respectively, and $\mathrm{LI}_{\max }$ is the maximum fractional light interception. Analysis of covariance was used to test for effects of harvest date and genotype on this relationship. As harvest date was found to have no significant effect, data from the five different harvest dates were pooled and Eq. (2) was solved for $k$ for each genotype after fitting a constant value of 0.971 for $\mathrm{LI}_{\max }$. A two-tailed $t$-test was used to determine whether $k$-values for each genotype were significantly different from one another at $P=0.05$.

\subsection{Data analysis}

Due to the unbalanced data set across experiments, variance components were estimated using the residual maximum likelihood (REML) method (Payne et al., 2007). Experiment, Background and Stature were fitted as fixed effects using Eq. (3), to test for main effects and interactions of factors and replicates were fitted as random effects.

Parameter Value $=$ Constant + Experiment + Background

$$
+ \text { Stature }+ \text { Experiment } \times \text { Background }
$$$$
+ \text { Experiment } \times \text { Stature }+ \text { Background }
$$$$
\times \text { Stature }+ \text { Experiment } \times \text { Background }
$$$$
\times \text { Stature }
$$

where Experiment is a factor with three levels (Exp1, Exp2, Exp3), Background (genetic background) a factor with five levels (A923171/R931945-2-2, A923171/R955637, R931945-2-2, R955637, R955343-1) and Stature a factor with two levels ( $-d w 3$, $+d w 3)$ ). GenStat was used for regression analyses (Payne et al., 2007).

\section{Results}

\subsection{Effects of stature on LAI, LI and $k$}

Tall (2-dwarf) plants intercepted significantly more light up to anthesis than their short (3-dwarf) comparisons $(P<0.001$, Tables 1 and 2). However, the effects of stature on light interception differed between experiments as indicated by a significant $\mathrm{E} \times \mathrm{S}$ interaction $(P=0.047$, Table 2$)$. Differences in light interception between tall and short canopies were much more pronounced in Exp1 and Exp2 than in Exp3 (Fig. 1). This was mainly due to greater LI by the short canopies (especially the short of R931945-2-2) in that experiment.

Stature did not affect total leaf area at anthesis and differences in LI did not generally seem to be associated with differences in LAI (Table 2). However, within the R931945-2-2 background there was a trend for greater leaf area of the tall compared with their corresponding short canopies (Table 1). Stature did affect tiller leaf area (Table 1), but in different directions in the different genetic backgrounds $(P=0.017)$. In Exp2 and 3, where main stem and tiller leaf area were measured separately, in both the R931945-2-2 and the R955343-1 backgrounds, 2-dwarfs had greater tiller leaf area compared to the 3-dwarfs. In the R955637 background, however, the 3-dwarf had greater tiller leaf area at anthesis compared with the 2-dwarf (Table 1).

The greater light interception of 2-dwarf compared with 3dwarf plants was also not associated with longer leaf area duration as 2-dwarfs actually reached anthesis slightly (1.2 days) earlier than 3-dwarfs (George-Jaeggli et al., 2011). dw3 had no effect on final leaf number of the main shoot as 2-dwarf and 3-dwarf genotypes had similar leaf numbers (data not shown). 
Table 1

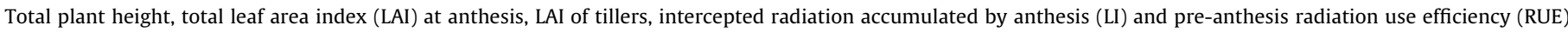

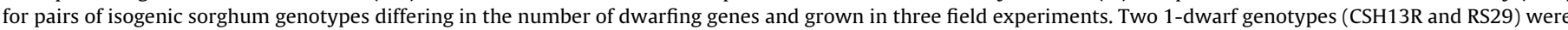
grown in Exp2 only, but were not included in the cross experimental data analysis. Values shown for those two genotypes are replicate means.

\begin{tabular}{|c|c|c|c|c|c|c|c|}
\hline Experiment (E) & Genetic Background (B) & Stature (S) & Plant height $(\mathrm{cm})$ & LAI (anth) $\left(\mathrm{m}^{2} \mathrm{~m}^{-2}\right)$ & LAI Tillers (anth) $\left(\mathrm{m}^{2} \mathrm{~m}^{-2}\right)$ & $\mathrm{LI}\left(\mathrm{MJ} \mathrm{m}^{-2}\right)$ & $\operatorname{RUE}\left(\mathrm{g} \mathrm{MJ}^{-1}\right)$ \\
\hline 1 & A923171/R931945-2-2 & 2-dwarf & 171 & 3.56 & - & 583 & 1.47 \\
\hline 1 & A923171/R931945-2-2 & 3-dwarf & 110 & 3.39 & - & 545 & 1.22 \\
\hline 3 & A923171/R931945-2-2 & 2-dwarf & 170 & 3.77 & 1.00 & 552 & 1.88 \\
\hline 3 & A923171/R931945-2-2 & 3-dwarf & 111 & 3.12 & 0.33 & 569 & 1.29 \\
\hline 1 & R931945-2-2 & 2-dwarf & 130 & 3.67 & - & 512 & 1.41 \\
\hline 1 & R931945-2-2 & 3-dwarf & 91 & 3.25 & - & 483 & 1.09 \\
\hline 2 & R931945-2-2 & 2-dwarf & 133 & 4.51 & 1.94 & 627 & 1.31 \\
\hline 2 & R931945-2-2 & 3-dwarf & 93 & 4.26 & 0.94 & 557 & 1.28 \\
\hline 3 & R931945-2-2 & 2-dwarf & 149 & 3.14 & 0.86 & 570 & 1.34 \\
\hline 3 & R931945-2-2 & 3-dwarf & 98 & 3.57 & 0.77 & 589 & 1.12 \\
\hline 1 & A923171/R955637 & 2-dwarf & 163 & 3.10 & - & 593 & 1.43 \\
\hline 1 & A923171/R955637 & 3-dwarf & 120 & 3.40 & - & 552 & 1.36 \\
\hline 1 & R955637 & 2-dwarf & 154 & 3.25 & - & 517 & 1.36 \\
\hline 1 & R955637 & 3-dwarf & 109 & 3.73 & - & 446 & 1.45 \\
\hline 2 & R955637 & 2-dwarf & 142 & 4.09 & 1.77 & 640 & 1.43 \\
\hline 2 & R955637 & 3-dwarf & 115 & 4.65 & 2.31 & 562 & 1.57 \\
\hline 3 & R955343-1 & 2-dwarf & 115 & 3.84 & 2.08 & 601 & 1.43 \\
\hline 3 & R955343-1 & 3-dwarf & 96 & 3.68 & 1.34 & 574 & 1.20 \\
\hline 2 & CSH13R & 1-dwarf & 252 & 6.52 & 2.73 & 1177 & 1.42 \\
\hline 2 & RS29 & 1-dwarf & 206 & 6.10 & 1.94 & 1092 & 1.28 \\
\hline
\end{tabular}

Table 2

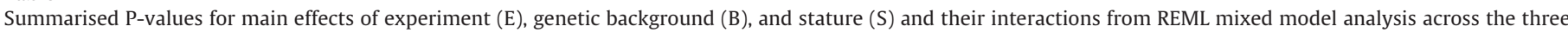
field experiments for each trait.

\begin{tabular}{|c|c|c|c|c|c|c|c|}
\hline & $\mathrm{E}$ & $\mathrm{B}$ & $\mathrm{S}$ & $\mathrm{E} \times \mathrm{B}$ & $\mathrm{E} \times \mathrm{S}$ & $\mathrm{B} \times \mathrm{S}$ & $\mathrm{E} \times \mathrm{B} \times \mathrm{S}$ \\
\hline Leaf area index at anthesis & ${ }_{* * *}$ & ${ }^{*}$ & n.s. & n.s. & n.s. & n.s. & n.s. \\
\hline Leaf area index of tillers at anthesis & ${ }^{* * *}$ & $* * *$ & ${ }^{*}$ & $* *$ & n.s. & ${ }_{* * *}^{* *}$ & n.a. \\
\hline Intercepted radiation accumulated by anthesis & *** & ** & $* * *$ & n.s. & ${ }^{*}$ & n.s. & n.s. \\
\hline Radiation use efficiency (pre-anthesis) & n.s. & *** & $* * *$ & n.s. & $* *$ & & n.s. \\
\hline
\end{tabular}

n.s.: not significant $(P>0.05)$, n.a.: not applicable (due to incomplete levels of comparison across all three experiments).

* Significant at $P<0.05$.

** Significant at $P<0.01$.

*** Significant at $P<0.001$

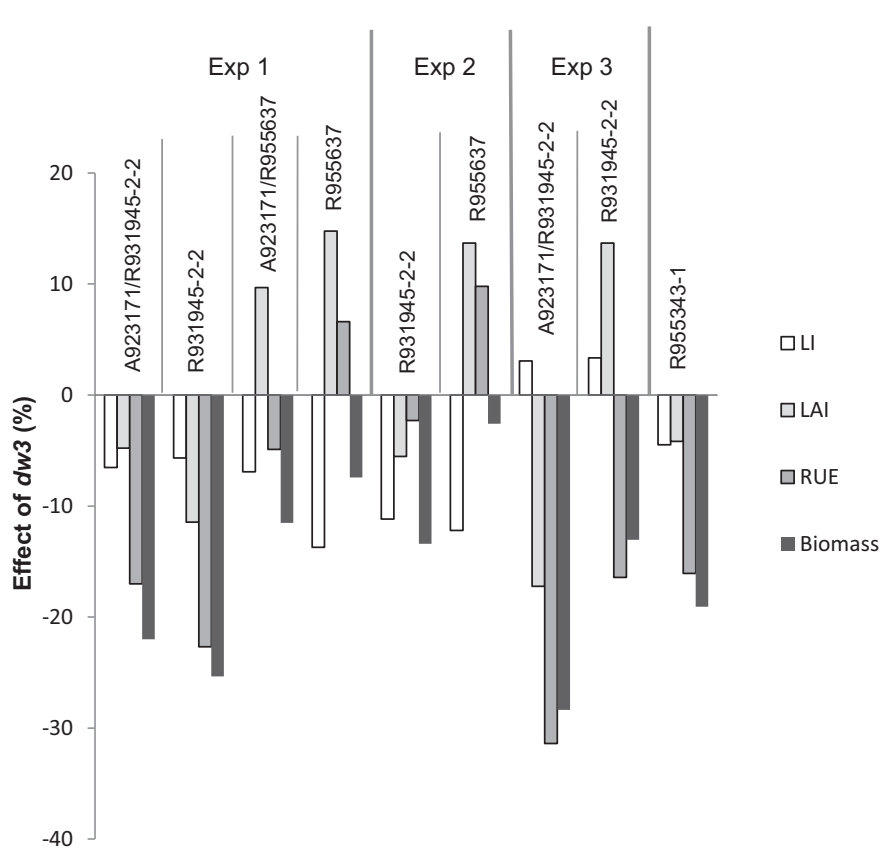

Fig. 1. Effect of presence of $d w 3$ on light interception (LI), leaf area index (LAI), radiation use efficiency (RUE) and shoot biomass at anthesis for each genetic background by experiment combination. The effect in each case is presented as percent change relative to the 2-dwarf. Shoot biomass data have been published previously (George-Jaeggli et al., 2011).
While neither total LAI, nor leaf area duration seemed to explain the greater light interception of the two 2-dwarfs compared with the 3-dwarfs, both of these factors contributed to the greater light interception of CSH13R and RS29. These two 1-dwarf hybrids intercepted nearly $100 \%$ more light than the 3-dwarf genotypes (Table 1 ), but they also had nearly $50 \%$ greater LAI and flowered around 10 days later than the 3-dwarfs.

Stature had a significant effect on $k(P=0.025)$ in $\operatorname{Exp} 2$ and $k$ was greater in the 2-dwarfs compared with their 3-dwarf comparisons (Table 3). Within individual pair comparisons, the difference was very small for the R931945-2-2 isogenic pair (Fig. 3a), but more substantial in the R955637 pair (Fig. 3b). In comparison, the two 1-dwarf hybrids had high values of $\mathrm{k}$ (Table 3 ). Across the six entries (Table 3 ), there was a significantly negative linear relationship between $\mathrm{k}$ and the number of dwarfing genes $\left(R^{2}=0.67, n=6\right.$, $P=0.029$ ).

\subsection{Effects of stature on RUE}

Stature had a significant effect on pre-anthesis RUE $(P<0.001$, Table 2), with tall types generally having greater RUE than their short counterparts (Table 1, Fig. 1). However, the effects of stature on RUE depended on genetic background as the $\mathrm{B} \times \mathrm{S}$ interaction was significant $(P=0.039$, Table 2$)$. The effect of stature on RUE was largest in the R931945-2-2 background and smallest in the R955637 background. In addition, there was a significant $\mathrm{E} \times \mathrm{S}$ interaction $(P=0.002)$, as the effect of stature on RUE tended to be smallest in Exp2 (Table 1, Fig. 1). Consistent with this, the 1-dwarf 
Table 3

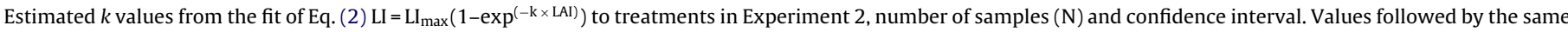
letter are not significantly different at $P<0.05$.

\begin{tabular}{|c|c|c|c|c|c|}
\hline Genetic Background & Stature & Number of dwarfing genes & Confidence Interval & Estimated $k$ & $\mathrm{~N}$ \\
\hline R931945-2-2 & 2-dwarf & 2 & $0.336-0.344$ & $0.34^{\mathrm{c}}$ & 50 \\
\hline R931945-2-2 & 3-dwarf & 3 & $0.326-0.333$ & $0.33^{\mathrm{d}}$ & 57 \\
\hline R955637 & 2-dwarf & 2 & $0.354-0.362$ & $0.36^{\mathrm{b}}$ & 47 \\
\hline R955637 & 3-dwarf & 3 & $0.284-0.291$ & $0.29^{e}$ & 64 \\
\hline CSH13R & 1-dwarf & 1 & $0.353-0.367$ & $0.36^{\mathrm{b}}$ & 50 \\
\hline RS29 & 1-dwarf & 1 & $0.385-0.403$ & $0.39^{\mathrm{a}}$ & 45 \\
\hline
\end{tabular}

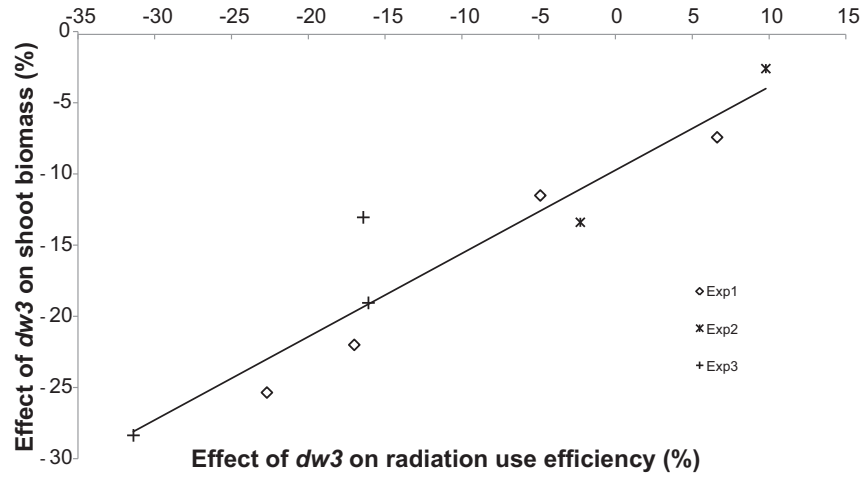

Fig. 2. Effect of presence of $d w 3$ on biomass versus effect of presence of $d w 3$ on radiation use efficiency for each genetic background by experiment combination (pre-anthesis data). The effect in each case is presented as percent change relative to the 2-dwarf. The line represents the fitted linear regression with the equation $y=355.75 x+81.94, R^{2}=0.89, P<0.001$. Shoot biomass data have been published previously (George-Jaeggli et al., 2011)

genotypes, which were only grown in Exp2, had similar RUE to the 2-dwarf and 3-dwarf isogenic lines. The small effect of stature on RUE in Exp2 was associated with low effects of stature on biomass in that experiment, indicating that a large difference in RUE between the tall and dwarf mutants was associated with a large difference in biomass accumulation $\left(R^{2}=0.88, n=9, P<0.001\right.$, Fig. 2$)$

\section{Discussion}

Increased plant height due to the absence of the $d w 3$ dwarfing gene has been associated with increased shoot biomass at anthesis (George-Jaeggli et al., 2011). As differences in shoot biomass were largely due to differences in stem biomass, 2-dwarfs had more stem reserves per grain available for translocation which was beneficial for grain size and (dependent on environmental and genetic background effects on grain number) led to increased grain yield in some cases (George-Jaeggli et al., 2011). In this paper we examine the factors underpinning the differences in shoot biomass accumulation between tall (2-dwarf) and short (3-dwarf) sorghum.

If water and nutrients are non-limiting, biomass production can be represented by the product of light interception (LI), and radiation use efficiency (RUE). LI in turn depends on $k$ and LAI. There was no clear indication of a single physiological determinant that exclusively underpinned biomass differences between height isolines in our experiments. The results showed some differences in all three determinants, LI, $k$, and RUE, but their importance differed among genetic backgrounds and experiments. We conclude that the genetic background in which the near-isogenic pairs were developed significantly affected the response to the presence of $d w 3$, which is supported by the fact that even the extent of height reduction varied among the pairs. For example, $d w 3$ reduced total plant height by about $50 \mathrm{~cm}$ in the R931945-2-2 genetic background, $40 \mathrm{~cm}$ in the R955637 background and only $20 \mathrm{~cm}$ in R955343-1. Any attempt to manipulate height in sorghum to increase grain yield potential would have to take into consideration whether and if so, which dwarfing alleles would be involved and the interactions that might exist with genetic background and environmental factors.

\subsection{The context dependency of the effects of $d w 3$ affected radiation capture}

Stature significantly affected LI and on average 2-dwarfs intercepted about 6\% more light by anthesis than their 3-dwarf comparisons, although this effect differed among experiments (Tables 1 and 2, Fig. 1). Light interception, in turn, depends on green leaf area and $k$, but none of these factors exclusively affected LI across the different genotypes. While total LAI was not significantly different between tall and short types, tall types had more tiller leaf area than their short counterparts in two of the genetic backgrounds (Table 1). This is consistent with a trend for fewer tillers in the 3-dwarfs compared with their 2-dwarf counterparts

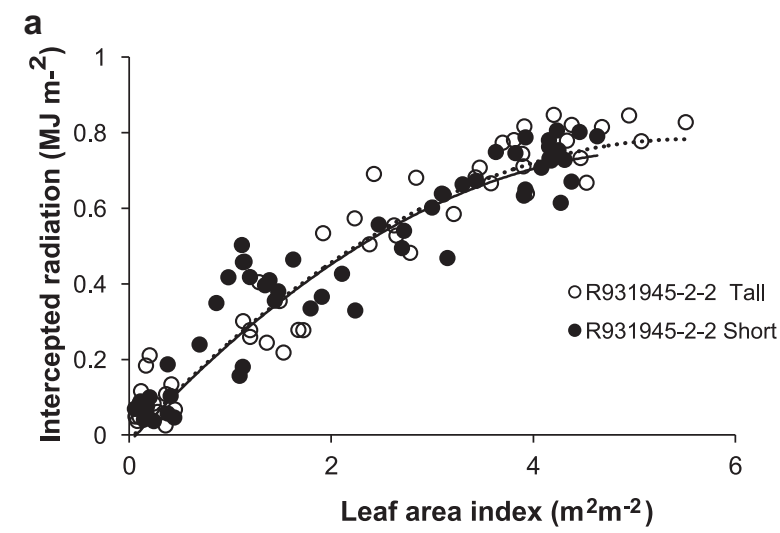

b

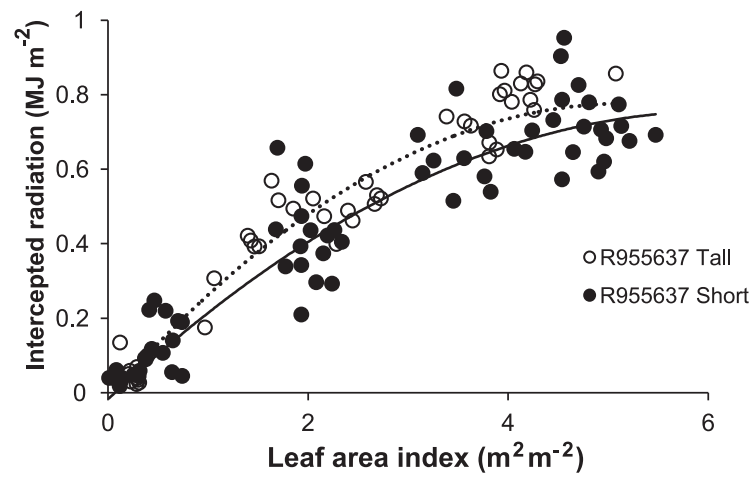

Fig. 3. Fraction of intercepted radiation (LI) versus cumulative leaf area index (LAI) from the top of the canopy for isogenic pairs of (a) R931945-2-2 and (b) R955637 (b) in Experiment 2. Data points are LI versus cumulative LAI for each canopy stratum and replicate measured on DAS 29, 58, 70 and 85 . Curves are fitted values for the equation $\mathrm{LI}=\mathrm{LI}_{\max }\left(1-\exp { }^{(-k \times \mathrm{LAI})}\right)$ with $\mathrm{LI}_{\max }=0.97$ and $k$ values from Table $3 . R^{2}$ values for goodness of fit are 0.96 and 0.90 for R931945-2-2 tall ( $\bigcirc$, dotted curve) and R931945-2-2 short ( $\square$, solid curve), respectively and 0.96 and 0.97 for R955637 tall ( $\bigcirc$, dotted curve) and R955637 short ( $\square$, solid curve), respectively. 
(George-Jaeggli et al., 2011). Reduced tiller number due to the presence of $d w 3$ has been reported previously (Hadley et al., 1965; Campbell and Casady, 1969).

While main stem leaves in sorghum are opposite and therefore directly above one another, tiller leaves tend to grow in between the main stem leaves into different directions and greater leaf area on tillers might have led to reduced shading and thus greater light interception per unit of leaf area in the tall types, especially in the R931945-2-2 and R955343-1 backgrounds that have more horizontal leaves than R955637. The R931945-2-2 line is further known as a low tillering line and the extra tillers when $d w 3$ is absent seem to have a positive effect on total LAI. Together with a slightly greater $k$ (Table 3 ) this might explain the greater LI of the tall types in this genotype. However, greater tiller number did not explain the increased LI of the tall type with the R955637 background as tiller leaf area was either similar (Exp1) or slightly reduced (Exp2) in the tall compared with the short type in the R955637 pair (Table 1). Greater light interception by the tall type of this genotype must therefore to a greater extent be due to a difference in $k$, which is supported by the results from $\operatorname{Exp} 2$ (Table 3). In Exp3, the trend for greater tiller leaf area in the tall types was generally much less pronounced in all of the pairs and tall and short types also intercepted similar amounts of radiation in that experiment. Environmental interactions, such as the balance between temperature and radiation conditions, may alter the tillering response (Kim et al., 2006) and possibly explain some of the differences in response between experiments. For example, there was lower radiation in Exp3 for a similar high temperature, which may have led to smaller differences in tiller number between short and tall types. This shows how intrinsic characteristics of the background genotype, such as propensity to tiller, affect the response to $d w 3$, but this interaction is further affected by environmental factors.

Interestingly, a large part of the success of the semi-dwarfing genes in increasing grain yield of wheat and rice during the Green Revolution was due to their positive effects on tiller number (Khush, 2001). This further highlights how important it is to assess the effects of dwarfing genes depending on context.

Similarly, differences in $k$ between tall and short types were significant, but quite small and possibly of little consequence in the R931945-2-2 background (Table 3). The difference was much greater in the $\mathrm{R} 955637$ background. This may also be due to intrinsic differences between the two genotypic backgrounds. While R931945-2-2 has horizontal leaves, the leaves of R955637 are more erect. The large decrease in $k$ in the R55637 genotype when $d w 3$ was present indicates that the leaves in the short canopy were even more erect. While we did not measure leaf angle, we did observe that the 3-dwarf of R955637 indeed had even more erect leaves than its 2-dwarf comparison. Canopies with more erect leaves have previously been associated with lower $k$ values (Goudriaan, 1988). It is likely that the small $k$ in the short canopy of R955637 led to lower intercepted radiation despite greater LAI. However, canopies with low light extinction coefficient and greater leaf area index have been described as more productive as radiation is distributed at a lower intensity level (below light saturation) over a larger leaf area (Fischer and Wilson, 1975). This is similar to the elevated RUE associated with an increased proportion of diffuse radiation due to more effective distribution of light through the canopy (Hammer and Wright, 1994). Hence, differences in $k$ might underpin differences in RUE.

While we observed a negative correlation between the number of dwarfing genes and $k$, the opposite was found in wheat, where $k$ increased with increasing dosage of dwarfing alleles (Miralles and Slafer, 1997). This is further evidence that the effects of dwarfing genes on canopy characteristics are dependent on genetic background in interaction with the environment.

\subsection{The context dependency of the effects of $d w 3$ likely also affected the RUE response}

RUE was significantly affected by stature and on average 2dwarfs had $10 \%$ greater RUE than 3 -dwarfs (Table 1 ). However, as indicated by significant $\mathrm{B} \times \mathrm{S}$ and $\mathrm{E} \times \mathrm{S}$ interactions (Table 2), this effect of stature also depended on the genetic background and environment and on two occasions, 3-dwarfs with the R955637 background actually had slightly greater RUE than their 2-dwarf comparisons (Fig. 1). As greater RUE in the short compared with the tall types was only observed in the R955637 genotype and the 3-dwarf of that genotype also had the lowest $k$ values, it is plausible that more even distribution of light compensated for the reduction in RUE that was associated with dwarfing in the other genotypes. Conversely, the lower RUE in the short R931945-2-2 was associated with only a small change in $k$ (Table 3 ). While such interactions with genetic background may have led to the observed discrepancies in response to dwarfing among pairs, inconsistencies in RUE responses across experiments (i.e. reduction in RUE in the short type of the R931945-2-2 inbred pair in Exp1 and Exp3, but not Exp2) are likely due to environmental factors. Presence of $d w 3$ mainly affected RUE in Exp3, but LI in Exp2, and both LI and RUE in Exp1 (Fig. 1). This environment context dependency may explain the contrast in results for CSH13R between Exp2, where CSH13R differed from other genotypes in LI, rather than RUE (Table 1), and the results from the previous study by Hammer et al. (2010), who reported that CSH13R had greater RUE, rather than greater LI than 3-dwarf sorghum. Changes to the radiation environment (Sinclair, 1986; Wright et al., 1993; Sinclair and Muchow, 1999), temperature (Garcia et al., 1988; Hammer et al., 1989; Bell et al., 1992; Andrade et al., 1993; Wright et al., 1993) and vapour-pressure deficit (Stockle and Kiniry, 1990) have all been reported to affect RUE. Furthermore, interactions between the effects of $d w 3$ on tiller number and the environment are plausible. Such environment by allele interactions have been described for the wheat semi-dwarfing genes (Mathews et al., 2006).

A negative correlation between RUE and increasing dosage of dwarfing alleles was also observed for wheat (Miralles and Slafer, 1997). This supports the idea that RUE is likely a main driver of differences in biomass accumulation between tall and short sorghum, but interactions between $d w 3$ and both the genetic backgrounds in which the near-isogenic pairs were developed and the environments in which these were grown, have masked this effect in our experiments.

Many reported values of RUE for grain sorghum during the vegetative phase are within the range of $1.2-1.3 \mathrm{~g} \mathrm{MJ}^{-1}$ total solar radiation (Muchow and Davis, 1988; Muchow and Sinclair, 1994; Gilbert et al., 2003). The RUE values found in some of the tall types in this study were considerably greater (around 20\%) than these published values for elite 3-dwarf hybrids. However, the large increase in RUE of the 1-dwarf CSH13R that was reported earlier (Hammer et al., 2010) was not found. Rather than increased RUE, both 1dwarfs (CSH13R and RS29) showed greater radiation interception (Table 1) compared with the shorter 2- and 3-dwarfs. However, the RUE value found for the tall type of the A923171/R931945-2-2 pair in Exp3 was similar to the very high RUE reported from that earlier study with CSH13R. These differences with previously published experiments are further confirmation of the context dependency of the effect of $d w 3$ on RUE.

Therefore, interactions between $d w 3$ and genetic background, but also interactions with environment are likely to have modulated the importance of RUE, LI and $k$ in determining biomass production. Such interactions would have to be taken into account, if breeding for taller sorghum to improve yield potential was envisaged. 


\subsection{Factors that might explain greater RUE of tall plants}

Under well-watered conditions, RUE is dependent on the lightsaturated leaf photosynthetic rate (Sinclair and Horie, 1989) which in turn is either related to efficiencies within the photosynthetic pathway itself or decreased maintenance respiration costs. For example, increased leaf nitrogen content is often an indication of greater photosynthetic rate and radiation use efficiency (Sinclair, 1986; Muchow and Davis, 1988). Although greater RUE of maize compared to 3-dwarf sorghum has been associated with greater SLN of maize (Muchow and Davis, 1988), it is unlikely greater RUE of 2-dwarf hybrids was associated with increased SLN. This is supported by data from a different study with CSH13R which show that its SLN is in fact lower than that of some 3-dwarf hybrids, because of dilution of leaf $\mathrm{N}$ due to larger individual leaf size and increased stem $\mathrm{N}$ demand that was not compensated by increased $\mathrm{N}$ uptake (van Oosterom et al., 2010).

The RUE values reported here are based on above-ground biomass only. The restriction in stem elongation in the presence of $d w 3$ may cause excess assimilates to be directed to root growth, resulting in an increased root-to-shoot ratio. This has been observed with the Rht semi-dwarfing genes in wheat (Miralles et al., 1997) and the sdw1 semi-dwarfing gene in barley (Chloupek et al., 2006), although root-shoot partitioning was unlikely to account for differences in RUE between maize and sorghum (Muchow and Davis, 1988). Root mass across sorghum genotypes has been found to range from 10 to $30 \%$ of total plant mass (Hammer et al., 1997; Choudhury, 2001) and changes in root-to-shoot ratio are therefore theoretically large enough to account for the changes in aboveground biomass of up to $20 \%$ in response to the sorghum dwarfing gene (George-Jaeggli et al., 2011).

\section{Conclusion}

$d w 3$ negatively affected sorghum shoot biomass mainly via a reduction in stem mass. This was previously shown to have negative effects on seed size which in some backgrounds and environments led to reduced grain yield, but not in others. The factors leading to a biomass reduction also strongly depended on genetic background and environment and were not exclusively due to either amount of light intercepted, canopy light extinction, or radiation use efficiency. While 2-dwarf plants intercepted more light than 3-dwarfs, (often associated with increased tillering), this increase did not explain all of the difference in biomass and RUE was also greater in some 2-dwarfs. However, the canopy light extinction coefficient was consistently reduced in the short compared with the taller plants and it was particularly small in the R955637 background, possibly explaining why this genotype did not show a reduction in RUE and biomass in response to the dwarfing gene. Measurements of root biomass are needed to clarify whether differences in root-shoot partitioning may also have contributed to observed differences in RUE. Inconsistencies across experiments may be due to variable environment by allele interactions. These context dependencies need to be taken into consideration if breeding programmes want to target taller stature in order to potentially increase grain yield.

\section{Role of the funding source}

This research was financially supported by the Grains Research and Development Corporation (GRDC) and the Queensland Government. Neither organisation had any input in experimental design, data collection and interpretation of results, nor in the decision to submit this paper for publication.

\section{Acknowledgement}

We gratefully thank Scott Chapman for his input into the conception of these experiments and Colleen Hunt and Greg McLean for their advice on data analysis.

\section{References}

Andrade, F.H., Uhart, S.A., Cirilo, A., 1993. Temperature affects radiation use efficiency in maize. Field Crop Res. 32, 17-25.

Austin, R.B., Bingham, J., Blackwell, R.D., Evans, L.T., Ford, M.A., Morgan, C.L., Taylor, M., 1980. Genetic improvements in winter wheat yields since 1900 and associated physiological changes. J. Agr. Sci. Camb. 94, 675-689.

Bell, M.J., Wright, G.C., Hammer, G.L., 1992. Night temperature affects radiation-use efficiency in peanut. Crop Sci. 32, 1329-1335.

Borner, A., Worland, A.J., Plaschke, J., Schumann, E., Law, C.N., 1993. Pleiotropic effects of genes for reduced height $(R h t)$ and day-length insensitivity $(P d P)$ on yield and its components for wheat grown in middle Europe. Plant Breeding 111, 204-216.

Campbell, L.G., Casady, A.J., 1969. Effects of a single height gene (Dw3) of Sorghum bicolor (L.) Moench at 1-dwarf and 2-dwarf height levels. Crop Sci. 9, 828-830.

Campbell, L.G., Casady, A.J., Crook, W.J., 1975. Effects of a single height gene $\left(D w_{3}\right)$ of sorghum on certain agronomic characters. Crop Sci. 15, 595-599.

Casady, A.J., 1967. Effects of a single height gene $\left(D w_{3}\right)$ of Sorghum vulgare Pers. on certain culm and leaf blade characteristics. Crop Sci. 7, 595-598.

Chloupek, O., Forster, B., Thomas, W.B., 2006. The effect of semi-dwarf genes on root system size in field-grown barley. Theor. Appl. Genet. 112, 779-786.

Choudhury, B.J., 2001. Modeling radiation- and carbon-use efficiencies of maize, sorghum and rice. Agr. Forest Meteorol. 106, 317-330.

Doggett, H., 1988. Sorghum. Longman Scientific \& Technical.

Fischer, K.S., Wilson, G.L., 1975. Studies of grain production in Sorghum bicolor (L.) Moench VI. Profiles of photosynthesis, illuminance and foliage arrangement. Aust. J. Agr. Res. 26, 31-41.

Flintham, J.E., Borner, A., Worland, A.J., Gale, M.D., 1997. Optimizing wheat grain yield: effects of Rht (gibberrellin-insensitive) dwarfing genes. J. Agri. Sci. Camb. $128,11-25$

Gale, M.D., Youssefian, S., 1985. Dwarfing genes in wheat. In: Russell, G.E. (Ed.), Progress in plant breeding. Butterworths, London, pp. 1-35.

Garcia, R.L., Kanemasu, E.T., Blad, B.L., Bauer, A., Hatfield, J.L., Major, D.J., Reginato, R.J., Hubbart, K.G., 1988. Interception and use efficiency of light in winter wheat under different nitrogen regimes. Agr. Forest Meteorol. 44, 175-186.

George-Jaeggli, B., Jordan, D.R., van Oosterom, E.J., Hammer, G.L., 2011. Decrease in sorghum grain yield due to the dw3 dwarfing gene is caused by reduction in shoot biomass. Field Crop. Res. 124, 231-239.

Gilbert, R.A., Heilman, J.L., Juo, A.S.R., 2003. Diurnal and seasonal light transmission to cowpea in sorghum - cowpea intercrops in Mali. J. Agron. Crop Sci. 189, 21-29.

Goudriaan, J., 1988. The bare bones of leaf-angle distribution in radiation models for canopy photosynthesis and energy exchange. Agr. Forest Meteorol. 43, 155-169.

Graham, D., Lessman, K.J., 1966. Effect of height on yield and yield components of two isogenic lines of Sorghum vulgare Pers. Crop Sci. 6, 372-374.

Hadley, H.H., Freeman, J.E., Javier, E.Q., 1965. Effects of height mutations on grain yield in sorghum. Crop Sci. 5, 11-14.

Hammer, G.L., Farquhar, G.D., Broad, I.J., 1997. On the extent of genetic variation for transpiration efficiency in sorghum. Aust. J. Agr. Res. 48, 649-655.

Hammer, G.L., van Oosterom, E., McLean, G., Chapman, S.C., Broad, I., Harland, P., Muchow, R.C., 2010. Adapting APSIM to model the physiology and genetics of complex adaptive traits in field crops. J. Exp. Bot. 8, 2185-2202.

Hammer, G.L., Vanderlip, R.L., Gibson, G., Wade, L.J., Henzell, R.G., Younger, D.R., Warren, J., Dale, A.B., 1989. Genotype-by-environment interaction in grain sorghum II. Effects of temperature and photoperiod on ontogeny. Crop Sci. 29, 376-384.

Hammer, G.L., Wright, G.C., 1994. A theoretical anlaysis of nitrogen and radiation effects on radiation use efficiency in peanut. Aust. J. Agr. Res. 45, 575-589.

Jordan, D.R., Tao, Y., Godwin, I.D., Henzell, R.G., Cooper, M., McIntyre, C.L., 2003. Prediction of hybrid performance in grain sorghum using RFLP markers. Theor Appl. Genet. 106, 559-567.

Khush, G., 2001. Green revolution: the way forward. Nat. Genet. 2, 815-822.

Kim, H.K., van Oosterom, E.J., Hammer, G.L., 2006. Physiology and genetics of tillering in sorghum. In: Borrell, A.K., Henzell, R.G., Jordan, D.R. (Eds.), 5th Australian Sorghum Conference. Range Media Pty Ltd. Published on CDROM, Gold Coast, Australia, 30 Jan - 2 Feb.

Mathews, K.L., Chapman, S.C., Trethowan, R., Singh, R.P., Crossa, J., Pfeiffer, W., van Ginkel, M., DeLacy, I., 2006. Global adaptation of spring bread and durum wheat lines near-isogenic for major reduced height genes. Crop Sci. 46, 603-613.

Miralles, D.J., Katz, S.D., Colloca, A., Slafer, G.A., 1998. Floret development in near isogenic wheat lines differing in plant height. Field Crop. Res. 59, 21-30.

Miralles, D.J., Slafer, G.A., 1997. Radiation interception and radiation use efficiency of near-isogenic wheat lines with different height. Euphytica 97, 201-208.

Miralles, D.J., Slafer, G.A., Lynch, V., 1997. Rooting patterns in near-isogenic lines of spring wheat for dwarfism. Plant Soil 197, 79-86.

Monsi, M., Saeki, T., 1953. Ueber den Lichtfaktor in den Pflanzengesellschaften. Jpn. J. Bot. 14, 22-52. 
Morgan, P.W., Finlayson, S.A., 2000. Physiology and genetics of maturity and height In: Smith, C.W., Frederiksen, R.A. (Eds.), Sorghum. Origin, History, Technology, and Production. John Wiley \& Sons, Inc.

Muchow, R.C., Davis, R., 1988. Effect of nitrogen supply on the comparative productivity of maize and sorghum in a semi-arid tropical environment II. Radiation Interception and biomass accumulation. Field Crop. Res. 18, 17-30.

Muchow, R.C., Sinclair, T.R., 1994. Nitrogen response of leaf photosynthesis and canopy radiation use efficiency in field-grown maize and sorghum. Crop Sci. 34, 721-727.

Multani, D.S., Briggs, S.P., Chamberlin, M.A., Blakeslee, J.J., Murphy, A.S., Johal, G.S., 2003. Loss of MDR transporter in compact stalks of maize br2 and sorghum $d w 3$ mutants. Science 302, 81-84.

Payne, R.W., Murray, D.A., Harding, S.A., Baird, D.B., Soutar, D.M., 2007. GenStat for Windows, Introduction, 10th ed. VSN, International, Hemel Hempstead. Lawes Agricultural Trust.

Quinby, J.R., Karper, R.E., 1945. The inheritance of three genes that influence time of floral initiation and maturity date in milo. J. Am. Soc. Agron. 37, 916-936.

Quinby, J.R., Karper, R.E., 1954. Inheritance of height in sorghum. Agron. J. 46, 211-216.
Rebetzke, G.J., Richards, R.A., Fischer, V.M., Mickelson, B.J., 1999. Breeding long coleoptile, reduced height wheats. Euphytica 106, 159-168.

Sinclair, T.R., 1986. Water and nitrogen limitations in soybean grain production I. Model development. Field Crop. Res. 15, 125-141.

Sinclair, T.R., Horie, T., 1989. Leaf nitrogen, photosynthesis, and crop radiation use efficiency: a review. Crop Sci. 29, 90-98.

Sinclair, T.R., Muchow, R.C., 1999. Radiation use efficiency. Adv. Agron. 65, 215-265.

Stockle, C.O., Kiniry, J.R., 1990. Variability in crop radiation-use efficiency associated with vapour-pressure deficit. Field Crop. Res. 25, 171-181.

van Oosterom, E.J., Borrell, A.K., Chapman, S.C., Broad, I.J., Hammer, G.L., 2010. Functional dynamics of the nitrogen balance of sorghum: I. N demand of vegetative plant parts. Field Crop. Res. 115, 19-28.

van Oosterom, E.J., Hammer, G.L., 2008. Determination of grain number in sorghum. Field Crop. Res. 108, 259-268.

Wright, G.C., Bell, M.J., Hammer, G.L., 1993. Leaf nitrogen content and minimum temperature interactions affect radiation-use efficiency in peanut. Crop Sci. 33 , 476-481. 